\title{
Honokiol protects against epidural fibrosis by inhibiting fibroblast proliferation and extracellular matrix overproduction in rats post-laminectomy
}

\author{
DAOLIANG XU ${ }^{1-3^{*}}$, WEIMIN ZENG ${ }^{3 *}$, XUYAO HAN $^{3 *}$, TIANCHEN QIAN $^{3}$, JINGYU SUN $^{3}$, \\ FANGZHOU $\mathrm{QI}^{3}, \mathrm{CHEN} \mathrm{LIU}^{3}$, QUAN WANG ${ }^{1-3}$ and HAIMING JIN ${ }^{1-3}$ \\ ${ }^{1}$ Department of Orthopaedics, The Second Affiliated Hospital and Yuying Children's Hospital of Wenzhou Medical University; \\ ${ }^{2}$ Key Laboratory of Orthopaedics of Zhejiang Province, Wenzhou, Zhejiang 325027; ${ }^{3}$ The Second School of Medicine, \\ Wenzhou Medical University, Wenzhou, Zhejiang 325035, P.R. China
}

Received June 9, 2020; Accepted September 28, 2020

DOI: $10.3892 / \mathrm{ijmm} .2020 .4765$

\begin{abstract}
Epidural fibrosis (EF)-induced failed back surgery syndrome (FBSS) in patients post-laminectomy remains a medical challenge. Although the scarring mechanisms remain unclear, the majority of aetiological studies have reported fibroblast dysfunction. Honokiol, the major bioactive constituent of the magnolia tree, exerts a variety of pharmacological effects, including anti-proliferative and anti-fibrotic effects, on various cell types. The present study investigated whether honokiol attenuates EF progression. In vitro, it was found that honokiol inhibited excessive fibroblast proliferation induced by transforming growth factor- $\beta 1$ (TGF- $\beta 1$ ) and the synthesis of extracellular matrix (ECM) components, including fibronectin and type I collagen, in a dose-dependent manner. These effects were attributed to the ability of honokiol to suppress the activity of connective tissue growth factor (CTGF), which is indispensable for the progression of fibrosis. Mechanistically, honokiol attenuated the TGF- $\beta 1$-induced activation of the Smad2/3 and mitogen-activated protein kinase (MAPK) signalling pathways in fibroblasts. In vivo, honokiol reduced the proliferation of fibroblasts and the synthesis of ECM components, thus ameliorating EF in a rat model post-laminectomy. Taken together, these preclinical findings suggest that honokiol deserves further consideration as a candidate therapeutic agent for EF.
\end{abstract}

Correspondence to: Dr Quan Wang or Dr Haiming Jin, Department of Orthopaedics, The Second Affiliated Hospital and Yuying Children's Hospital of Wenzhou Medical University, 109 West Xueyuan Road, Wenzhou, Zhejiang 325027, P.R. China

E-mail: wangquancx@zju.edu.cn

E-mail: kkjinhaiming@126.com

${ }^{*}$ Contributed equally

Key words: honokiol, epidural fibrosis, fibroblasts, Smad2/3, mitogen-activated protein kinase

\section{Introduction}

Laminectomy is commonly used in the treatment of lumbar disc herniation and its associated conditions (1). However, up to $40 \%$ of patients suffer from failed back surgery syndrome (FBSS), which is characterized by recurrent and continuous pain following neurosurgical interventions, such as lumbar laminectomy (2-5). Extensive epidural fibrosis (EF), or scarring adjacent to the dura mater, may develop following lumbar laminectomy and may lead to clinically significant FBSS by compressing and irritating the surrounding anatomical structures (6-8). EF accounts for $24 \%$ of revision surgeries (9). Surgical scar excision is challenging and extremely risky; thus, biological therapies are receiving increasing attention (10-12).

Although the pathogenesis underlying the formation and development of EF remains largely unknown, excessive fibroblast proliferation and extracellular matrix (ECM) production reportedly play key roles (13-15). A number of studies have demonstrated that transforming growth factor- $\beta 1$ (TGF- $\beta 1$ ), the major factor triggering EF, regulates fibroblast proliferation and ECM production (14,16-18). Hence, efforts to inhibit TGF- $\beta 1$-associated signal transduction in order to reduce excessive fibroblast proliferation and ECM overproduction are increasing. The TGF- $\beta 1$-induced activation of the Smad2/3 signalling pathway plays a major role in fibroblast proliferation and ECM accumulation $(19,20)$. In addition, TGF- $\beta 1$ stimulation increases the levels of phosphorylated receptor-activated Smad2/3 transcription factors, which form heteromeric complexes with Smad4 and are then translocated to the nucleus. The heterocomplexes then initiate fibrosis by recruiting various transcription factors and binding to specific sequences in the promoter regions of target genes $(21,22)$. Additionally, mitogen-activated protein kinases (MAPKs), which play important roles in Smad-independent TGF- $\beta 1$ signalling, also regulate TGF- $\beta 1$-mediated stimulation $(21,23)$. Moreover, there is substantial evidence to indicate that the transcriptional activity of the Smad complex is regulated by the TGF- $\beta 1$-induced activation of MAPK $(23,24)$. Thus, the inhibition of TGF- $\beta 1$-related pathways, such as the Smad and MAPK pathways, to reduce the cell proliferation and ECM 
overproduction of fibroblasts is regarded as a potentially crucial target for the treatment of EF.

Honokiol [30,5-di-(2-propenyl)-1,10-biphenyl-2,40-diol], a small polyphenol, is a major bioactive constituent isolated from the traditional Chinese medicine, Magnolia officinalis (25). Previous pharmacological studies have demonstrated that honokiol exerts anti-inflammatory, antioxidant, anti-bacterial, antitumour, anti-calmodulin and neuroprotective effects, among others (25-29). A recent study reported that honokiol alleviated hypertrophic scarring by inhibiting excessive ECM deposition and hypertrophic scar-derived fibroblast proliferation (30). Similarly, honokiol has been reported to ameliorate fibrosis by inhibiting the expression of pro-fibrotic factors and ECM proteins in a rat model of renal fibrosis (31). Additional findings provide evidence that the promising anti-fibrotic effects of honokiol in rats with liver fibrosis are related to the suppression of the TGF- $\beta /$ Smad and MAPK signalling pathways (32). Based on these findings, it was hypothesized that honokiol may attenuate the development of EF. The present study examined its effects on the proliferation and ECM production of TGF- $\beta 1$-stimulated fibroblasts. Moreover, the protective role of honokiol against EF was further confirmed in a rat model post-laminectomy.

\section{Materials and methods}

Reagents and antibodies. Honokiol, purchased from Sigma-Aldrich; Merck KGaA, was freshly dissolved in DMSO. The purity of honokiol used in the present study was $>98 \%$. Fibronectin, connective tissue growth factor (CTGF; cat. no. ab6992), type I collagen (cat. no. ab260043), Smad2/3 (cat. no. ab202445), p-Smad2 (cat. no. ab188334), p-Smad3 (cat. no. ab52903), p-p38 (cat. no. ab178867), p-JNK (cat. no. ab124956), p-ERK (cat. no. ab201015), p38 (cat. no. ab170099), JNK (cat. no. ab179461), ERK (cat. no. ab184699) and GAPDH (cat. no. ab181602) antibodies, were purchased from Abcam); primary antibody against cyclin B1 (cat. no. sc-245), cyclin D1 (cat. no. sc-8396) and cyclin E (cat. no. sc-247) were purchased from Santa Cruz Biotechnology. Inc.; the goat anti-rabbit (cat. no. BS13271) and anti-mouse (cat. no. BS12471) IgG-HRP were purchased from Bioworld. Recombinant human TGF- $\beta 1$ was purchased from PeproTech Group, Inc. DMSO, carboxymethylcellulose (CMC) and collagenase I were purchased from Sigma-Aldrich; Merck $\mathrm{KGaA}$. Cell culture reagents were purchased from Gibco; Thermo Fisher Scientific, Inc.

Fibroblast culture. A total of 16 male Sprague-Dawley rats (3 months old; weight, 350-400 g), were purchased from the Animal Centre of the Chinese Academy of Sciences. Lumbar laminectomy was performed on rats as described in a previous study (33). The rats were housed under specific pathogen-free conditions at $25^{\circ} \mathrm{C}$ with a 12 -h light/dark cycle and free access to food and water. Epidural scar tissues were collected when the rats were sacrificed. The epidural scar tissues were placed in PBS to maintain moisture, then minced and incubated in a solution of collagenase type $\mathrm{I}(0.1 \mathrm{~g} / \mathrm{l})$ at $37^{\circ} \mathrm{C}$ for $3 \mathrm{~h}$ to separate the primary fibroblasts. Following enzymatic digestion, the isolated cells were incubated in Dulbecco's modified Eagle's medium (DMEM; Gibco; Thermo Fisher Scientific,
Inc.), supplemented with $10 \%$ foetal bovine serum and $1 \%$ antibiotic mixture of penicillin and streptomycin, for the culture of the cells. The cells were incubated at $37^{\circ} \mathrm{C}$ with a humid atmosphere of $95 \%$ air and $5 \% \mathrm{CO}_{2}$. The fibroblasts used in the present study were at passages 2 to 5 . All the cells were incubated at $37^{\circ} \mathrm{C}$ for $24 \mathrm{~h}$ until they reached $70-80 \%$ confluence. The cells were starved in serum-free DMEM for $24 \mathrm{~h}$, followed by supplementation with $10 \mathrm{ng} / \mathrm{ml}$ TGF- $\beta 1$ and/or honokiol for $2 \mathrm{~h}$ prior at various concentrations (1, 2.5, 5,10 or $20 \mu \mathrm{M}$ ), followed by incubation at $37^{\circ} \mathrm{C}$ for a further $72 \mathrm{~h}$.

Cell viability and proliferation. To determine the cytotoxicity of honokiol, the cells were incubated with various concentrations $(1,2.5,5,10$ or $20 \mu \mathrm{M})$ of honokiol for $72 \mathrm{~h}$. For the analysis of cell proliferation, the cells were seeded in 96-well plates for $24 \mathrm{~h}$ and then stimulated with TGF- $\beta 1$ and/or honokiol for $2 \mathrm{~h}$ prior at various concentrations $(1,2.5,5,10$ or $20 \mu \mathrm{M})$ for a further $72 \mathrm{~h}$. Subsequently, the cells were washed 3 times with phosphate-buffered saline (PBS), and then incubated for $2 \mathrm{~h}$ in CCK-8 solution (CCK-8; Dojindo, Tokyo, Japan), at $37^{\circ} \mathrm{C}$. A spectrophotometer (Thermo Fisher Scientific, Inc.) at $450 \mathrm{~nm}$ was used to measure the absorbance of the cells.

$E d U$ incorporation assay. The effects of honokiol on TGF- $\beta 1$-induced proliferation were determined using a Cell-Light EdU DNA cell kit (Guangzhou RiboBio Co., Ltd.,), according to the manufacturer's instructions. In brief, after being subjected to the appropriate treatments, fibroblasts were incubated at $37^{\circ} \mathrm{C}$ in EdU solution $(50 \mu \mathrm{mol} / 1)$ for $2 \mathrm{~h}$. The cells were then fixed in $4 \%$ formaldehyde for $30 \mathrm{~min}$ and incubated at room temperature with $0.5 \%$ Triton X-100 in PBS for $10 \mathrm{~min}$. After washing with PBS, Click-iT ${ }^{\mathrm{TM}}$ reaction cocktail was added to the plates for $30 \mathrm{~min}$, and the cells were then stained with Hoechst 33342 dye at room temperature for a further $30 \mathrm{~min}$. Proliferating cells were imaged under a fluorescent microscope (Nikon Corporation) and were counted using Image J software (NIH). A total of 5 fields were randomly selected for microscopic observation.

\section{Reverse transcription-quantitative polymerase chain reaction} $(R T-q P C R)$. Total RNA was extracted from the treated fibroblasts and epidural scar tissues using TRIzol reagent (Invitrogen; Thermo Fisher Scientific, Inc.), according to the manufacturer's instructions. The concentration was determined spectrophotometrically at $260 \mathrm{~nm}$ (NanoDrop 2000; Thermo Fisher Scientific, Inc.). Total RNA (1 $\mu \mathrm{g})$ was reverse transcribed to synthesize cDNA using PrimeScript Reverse Transcriptase (Takara Bio, Inc.). Subsequently, $5 \mu 1$ of $2 \mathrm{X}$ SYBR Master Mix, $0.25 \mu \mathrm{l}$ of each primer and $4.5 \mu \mathrm{l}$ of diluted cDNA were used for PCR amplification. The qPCR thermocycling conditions were as follows: $95^{\circ} \mathrm{C}$ for $3 \mathrm{~min}, 40$ cycles of $95^{\circ} \mathrm{C}$ for $30 \mathrm{sec}$, annealing at $60^{\circ} \mathrm{C}$ for $45 \mathrm{sec}$, and a final elongation step at $72^{\circ} \mathrm{C}$ for $20 \mathrm{sec}$. The CFX96 Real-Time PCR System (Bio-Rad Laboratories, Inc.) was used to conduct the reaction and detection. All mRNA quantification data were collected and normalized to the level of the housekeeping gene, GAPDH. The $2^{-\Delta \Delta \mathrm{Cq}}$ method (34) was used to calculate the relative mRNA levels of each target gene. The primers used are listed in Table I. 
Table I. Primer sequences used in RT-qPCR.

\begin{tabular}{llcr}
\hline Gene & \multicolumn{1}{c}{ Forward primer } & Reverse primer & Product size (bp) \\
\hline CTGF & 5'-TGGCTTGCTCAGGGTAACTG-3' & 5'-CTGCCTCCCAAACCAGTCAT-3' & 80 \\
Type I collagen & 5'-CCCAGCGGTGGTTATGACTT-3' & 5'-CGGCCACCATCTTGAGACTT-3' & 68 \\
Fibronectin & 5'-CCCCAACTGGTTACCCTTCC-3' & 5'-GGTGACGAAGGGGGTCTTTT-3' & 90 \\
GAPDH & 5'-AGTGCCAGCCTCGTCTCATA-3' & 5'-TGAACTTGCCGTGGGTAGAG-3' & 189 \\
\hline
\end{tabular}

Western blot analysis. The treated fibroblasts and epidural scar tissues were lysed with radioimmune precipitation assay (RIPA; Beyotime Institute of Biotechnology) buffer to extract whole-cell proteins. Protein concentration was determined using a BCA assay kit (cat. no. 23250; Pierce; Thermo Fisher Scientific, Inc.). Equal amounts (30 $\mu \mathrm{g}$ each) of total proteins were subjected to electrophoresis on sodium dodecyl sulphate polyacrylamide $10 \%$ gels and transferred onto nitrocellulose membrane (Life Technologies; Thermo Fisher Scientific, Inc.). After blocking, the membranes were probed with primary antibodies against CTGF, type I collagen, fibronectin, cyclin B1, cyclin D1, cyclin E, p-Smad2, p-Smad3, Smad2/3, p-p38, p-JNK, p-ERK, p38, JNK, ERK and GAPDH (all 1:1,000) overnight at $4^{\circ} \mathrm{C}$. The membranes were then incubated with appropriate secondary antibodies $(1: 3,000)$ for $2 \mathrm{~h}$ at room temperature. The protein bands were visualized by electrochemiluminescence plus reagent (Invitrogen; Thermo Fisher Scientific, Inc.). The ChemiDoc ${ }^{\mathrm{TM}}$ XRS Imaging System (Bio-Rad Laboratories, Inc.) was used to quantify the band intensity.

Immunofluorescence. Fibroblasts were plated on glass coverslips in 24-well plates. Following stimulation with TGF- $\beta 1$ $(10 \mathrm{ng} / \mathrm{ml}) \mathrm{and} /$ or various concentrations $(5,10$ or $20 \mu \mathrm{M})$ of honokiol for $2 \mathrm{~h}$ prior, cells were fixed in $4 \%$ formaldehyde for $10 \mathrm{~min}$, and permeabilized with $0.1 \%$ Triton $\mathrm{X}-100$ for 5 min, followed by blocking with $5 \%$ normal goat serum for $5 \mathrm{~min}$. The cells were then labelled with anti-Smad3 antibody (cat. no. ab40854; 1:500) overnight at $4^{\circ} \mathrm{C}$ and probed with FITC-conjugated anti-rabbit IgG antibody (cat. no. ab6717; $1: 3,000$ ) for $1 \mathrm{~h}$ at room temperature and DAPI (Roche Diagnostics $\mathrm{GmbH}$ ). Finally, the cells were photographed using a fluorescence microscope (Nikon Corporation).

Hepatotoxicity and survival rate assessment. The animals were arbitrarily divided into 3 groups $(n=15)$, treated with $0,10,20 \mathrm{mg} / \mathrm{kg}$ intragastrically every other day for 4 weeks until sacrificed. Then, the serum aspartate aminotransferase (AST), alanine aminotransferase (ALT) and albumin were tested colourimetrically by using commercially available kits (Biodiagnostics, Cairo, Egypt). In addition, survival rate was estimated using Kaplan Meier analysis.

Animal ethics statement and models. All experimental procedures for animal studies were carried out in compliance with the principles of International Laboratory Animal Care and the experimental protocol was approval by the Animal Care and Use Committee at the Wenzhou Medical College (approval no. wydw2017-0007). A total of 78 male
Sprague-Dawley rats (3 months old; weight, 350-400 g) were purchased from the Animal Centre of the Chinese Academy of Sciences. Rats were housed under specific pathogen-free conditions at $25^{\circ} \mathrm{C}$ with a 12-h light/dark cycle and free access to food and water. The rats were randomly assigned to the sham-operated (sham) group $(n=6$, treatment without laminectomy), the control group $(\mathrm{n}=24)$, the honokiol $10 \mathrm{mg} / \mathrm{kg}$ group $(n=24)$ and the honokiol $20 \mathrm{mg} / \mathrm{kg}$ group $(\mathrm{n}=24)$. The rats in each group were weighed and injected intraperitoneally with $2 \%(\mathrm{w} / \mathrm{v})$ pentobarbital $(40 \mathrm{mg} / \mathrm{kg})$ and fixed on the operation board in the prone position. Laminectomy was performed as described in a previous study (33). The hair of each rat was shaved around the first lumbar vertebra (L1), and the exposed skin was sterilized with povidone-iodine. A dorsal midline incision (T12-L3) was made to remove the spinous process and vertebral plate and to expose the dura mater at the L2 level. Close attention was paid not to traumatize the neural tissue. The rats in the sham group were not subjected to laminectomy, but only underwent the same surgical procedure and were exposed for $2 \mathrm{~min}$. After satisfactory haemostasis, the wound was surgically closed. Post-operatively, the rats in the honokiol group received honokiol (10 or $20 \mathrm{mg} / \mathrm{kg}$ ) dissolved in CMC intragastrically every other day until the rats were sacrificed, while the rats in the other 2 groups were administered the same volume of CMC. Daily monitoring of the rats was carried out to ensure their well-being and all animals were allowed free unrestricted activity. No animals were found dead during the duration of the experiment. All rats were euthanized by an overdose of pentobarbital sodium $(100-150 \mathrm{mg} / \mathrm{kg}$; intraperitoneally injected; cat. no. B005; Nanjing Jiancheng Bioengineering Institute) at 4 weeks post-operatively. Rat euthanasia was confirmed prior to disposing of the animal remains by the criteria of the AVMA euthanasia guidelines 2020 (35), including lack of pulse, breathing, corneal reflex, response to firm toe pinch and so on. The epidural scar and surrounding tissues were collected for subsequent analyses.

Macroscopic assessment. Macroscopic assessment was performed at 4 weeks post-operatively, to assess both the spaces between the dura mater and the surrounding soft tissues. The epidural scar adhesion was evaluated based on the Rydell classification (36) as follows: Grade 0, epidural scar tissue was not adherent to the dura mater; grade 1, epidural scar tissue was adherent to the dura mater, but easily dissected; grade 2, epidural scar tissue was adherent to the dura mater, and it was difficult to dissect without disrupting the dura matter; grade 3, epidural scar tissue was firmly adherent to the dura mater and could not be dissected. 
A

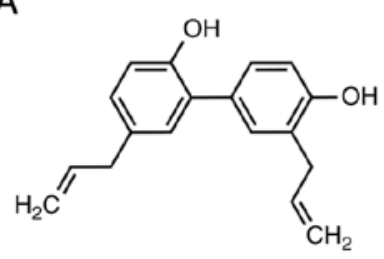

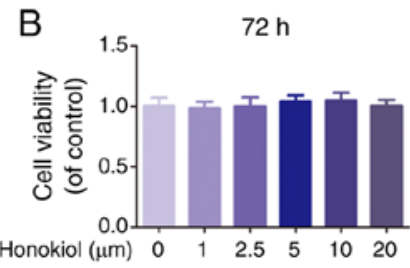

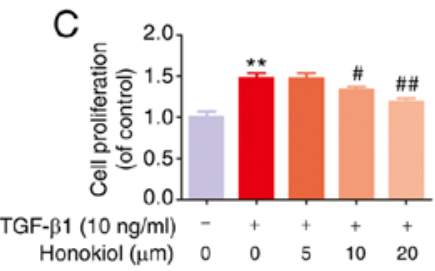

$\mathrm{F}$

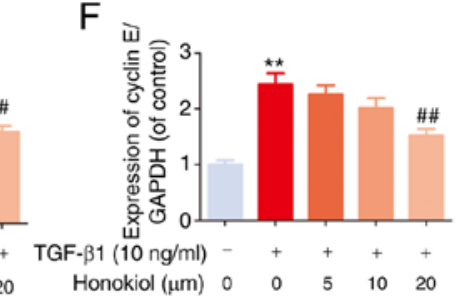

$\mathrm{H}$

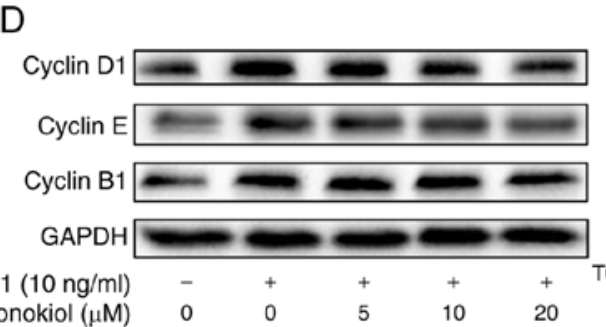

$\mathrm{E}$
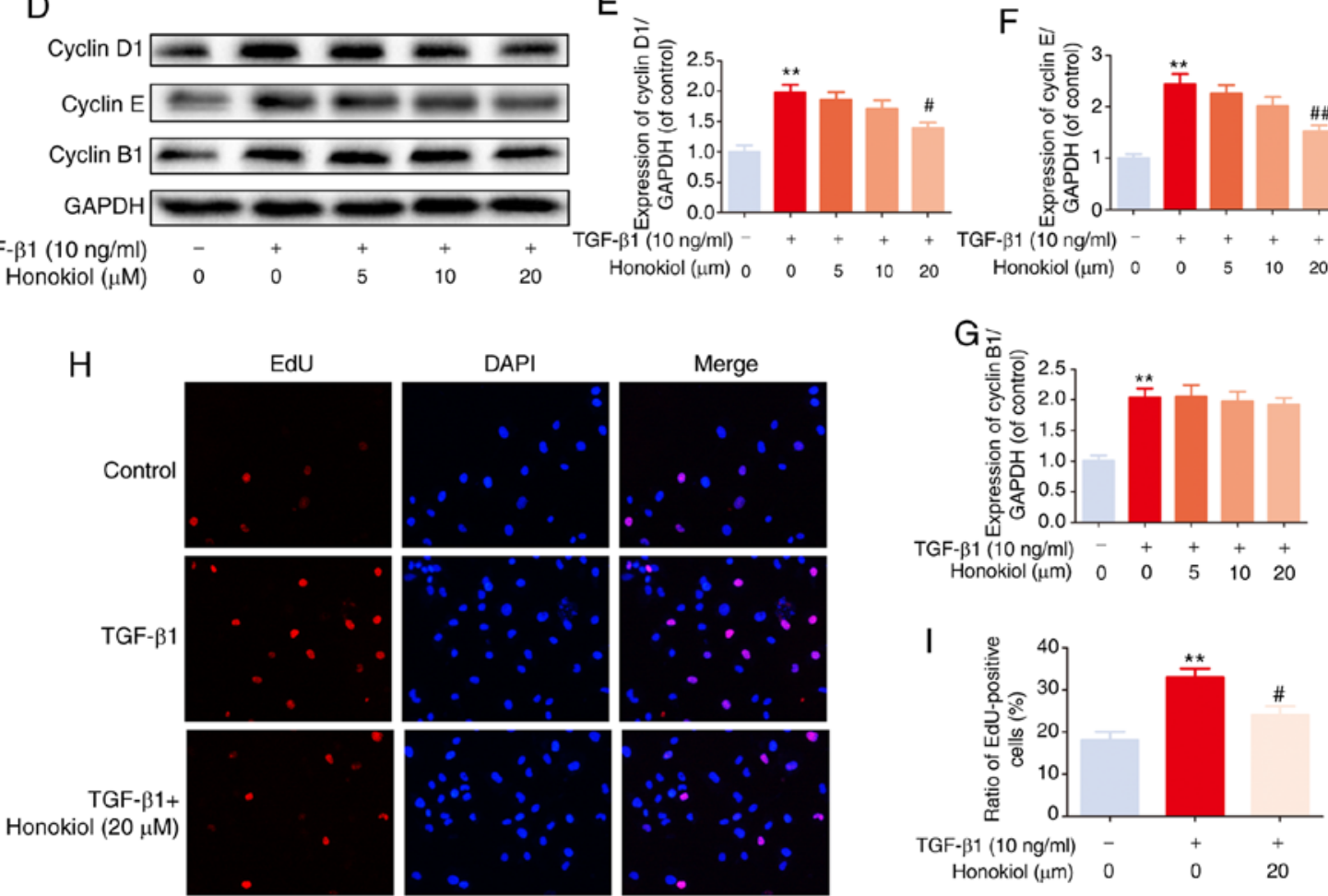

Figure 1. Effects of honokiol on toxicity and proliferation of fibroblasts. (A) Chemical structure of honokiol. (B) Fibroblasts were incubated with various concentrations of honokiol for $72 \mathrm{~h}$. (C) Fibroblasts were treated with $10 \mathrm{ng} / \mathrm{ml}$ TGF- $\beta 1$, alone or with the indicated concentrations of honokiol for $72 \mathrm{~h}$. (D) Effects of honokiol on cyclin D1, cyclin E and cyclin B1 induced by TGF- $\beta 1$ were examined by western blot analysis. (E-G) Bar diagram of the cyclin D1, cyclin E and cyclin B1 expression. (H) The active DNA synthesis of fibroblasts was detected by EdU incorporation assay (x100 magnification). (I) Ratios of EdU-positive cells. Data are presented as the means $\pm \mathrm{SEM},{ }^{* *} \mathrm{P}<0.01$, vs. the control group. ${ }^{\#} \mathrm{P}<0.05,{ }^{\# \#} \mathrm{P}<0.01$ compared with the TGF- $\beta 1$-stimulated group; $\mathrm{n}=3$.

Determination of hydroxyproline $(H P C)$ content. HPC content analysis was performed to observe the main signs of fibrosis. The HPC content of wet scar tissue obtained from the laminectomy site was determined as described in a previous study (37). The samples were lyophilized, ground and hydrolysed with $\mathrm{HCL}$ at $110^{\circ} \mathrm{C}$ for $24 \mathrm{~h}$. The hydroxyproline developer ( $\beta$-dimethylaminobenzaldehyde solution; Beyotime Institute of Biotechnology, Inc.) was then used to examine the samples and standards, and a spectrophotometer (Thermo Fisher Scientific, Inc.) was used to evaluate the absorbance of the solution was at $550 \mathrm{~nm}$. The HPC content per milligram of scar tissue was calculated.

Histopathological analysis. The rats from each group were sacrificed and histopathological analysis was performed at week 4 following surgery. The specimens, including the entire L1-L2 spinal column, the paraspinal muscles and epidural fibrotic tissue, were fixed in $4 \%$ paraformaldehyde and decalcified, then dehydrated and embedded in paraffin. The gross specimens were then sectioned at a thickness of $5 \mu \mathrm{m}$. The slides of each disc were stained with haematoxylin and eosin
(H\&E; Beyotime Institute of Biotechnology, Inc.) and Masson's trichrome stain (Beyotime Institute of Biotechnology, Inc.) at room temperature. Epidural scar adhesion was evaluated under an optical microscope (Olympus Corporation; x40 magnification), and the number of fibroblasts was counted under an optical microscope (Olympus Corporation; x200 magnification).

Statistical analysis. Statistical analyses were performed using SPSS 20.0 statistical software. The experiments were performed for 3 biological replicates and 3 technical replicates. All results are presented as the means \pm SEM. The variance of $\geq 2$ groups was analysed using one-way analysis of variance followed by Tukey-Kramer as post-hoc test. The Kruskal-Wallis test followed by Dunn's multiple comparison was used to analyse non-parametric data. Statistical significance was set at $\mathrm{P}<0.05$.

\section{Results}

Honokiol inhibits the TGF- $\beta 1$-induced proliferation of fibroblasts. The chemical structure of honokiol is presented in 
Table II. Degree of epidural adhesion according to Rydell's classification (36).

\begin{tabular}{lllll}
\hline & \multicolumn{4}{c}{ Grade } \\
\cline { 2 - 5 } Group & 0 & 1 & 2 & 3 \\
\hline Control & 0 & 0 & 2 & 4 \\
Honokiol $(10 \mathrm{mg} / \mathrm{kg})$ & 1 & 3 & 2 & 0 \\
Honokiol $(20 \mathrm{mg} / \mathrm{kg})$ & 2 & 3 & 1 & 0 \\
\hline
\end{tabular}

Fig. 1A. First, to ascertain the susceptibility of fibroblasts to honokiol, a dose-response experiment with various concentrations of honokiol $(0,1,2.5,5,10$ or $20 \mu \mathrm{M})$ was performed. Following $72 \mathrm{~h}$ of incubation, cell viability was assessed by CCK-8 assay. No significant differences were observed following $72 \mathrm{~h}$ of treatment with various concentrations of honokiol (Fig. 1B). Therefore, 5, 10, or $20 \mu \mathrm{M}$ were selected as the appropriate concentrations of honokiol for use in subsequent experiments. Second, to determine whether honokiol affects the proliferation of fibroblasts, the cells were incubated with various concentrations of honokiol in the presence of TGF- $\beta 1(10 \mathrm{ng} / \mathrm{ml})$ for $72 \mathrm{~h}$, and cell viability was assessed by CCK-8 assay. As shown in Fig. 1C, TGF- $\beta 1$ led to an increased fibroblast proliferation, and this was significantly reversed by honokiol treatment in a dose-dependent manner. To further confirm the anti-proliferative effects of honokiol, the protein levels of cyclin D1 and cyclin E, major cyclin proteins that are involved in the regulation of G0/G1 phase progression $(38,39)$, were examine by western blot analysis. In addition, the expression of cyclin B1, which plays a pivotal role in controlling the G2 to M phase transition and is widely used as a marker of cell proliferation $(39,40)$, was analysed. The results revealed that honokiol treatment induced a significant decrease in cyclin D1 and cyclin E expression in a dose-dependent manner, whereas cyclin B1 expression was not affected, suggesting that honokiol arrests fibroblast proliferation during the G0/G1 phase progression by inhibiting the expression of cyclin D1 and cyclin E (Fig. 1D-G). A similar anti-proliferative effect was observed in the TGF- $\beta 1$-stimulated fibroblasts, by EdU fluorescence staining. Treatment with honokiol $(20 \mu \mathrm{M})$ significantly reduced the percentage of EdU-positive cells (red; Fig. 1H and I). Taken together, these results suggested that pre-treatment with honokiol suppressed the increased fibroblast proliferation induced by TGF- $\beta 1$.

Honokiol suppresses TGF- $\beta 1$-induced ECM production. EF can trigger the increased expression of ECM components. To examine the effects of honokiol on TGF- $\beta 1$-induced ECM production, the expression of fibronectin and type I collagen, which are considered to be the main components of ECM, were examined by western blot analysis. As shown in Fig. 2, the stimulation of fibroblasts with TGF- $\beta 1$ induced a noticeable increase in the expression of fibronectin and type I collagen at both the gene and protein levels, which was reversed by honokiol treatment in a dose-dependent manner. These data demonstrated that honokiol prevented the ECM overproduction induced by TGF- $\beta 1$ in fibroblasts.
Honokiol inhibits TGF- $\beta 1$-induced CTGF expression. Previous studies have indicated that CTGF, as a matricellular protein of the CCN family of ECM-associated proteins, plays an important role in regulating ECM production and proliferation in various cell types $(14,17)$. In the present study, to further confirm the mechanisms through which honokiol participates in TGF- $\beta 1$-induced stimulation, RT-qPCR and western blot analysis of the gene and protein levels of CTGF were performed. As was expected, it was found that honokiol treatment effectively inhibited the noticeable TGF- $\beta 1$-induced increase in both the mRNA and protein levels of CTGF in a dose-dependent manner (Fig. 3). Taken together, these findings demonstrated that the protective role of honokiol may involve the inhibition of ECM overproduction and proliferation by suppressing the upstream protein, CTGF.

Honokiol inhibits TGF- $\beta 1$-induced Smad2/3 pathway activation. To further determine the mechanisms through which honokiol exerts its effects, the present study examined the activation of the $\mathrm{Smad} 2 / 3$ signalling pathway, which is involved in classic TGF- $\beta 1$-induced signalling, by western blot analysis. Regardless of the presence of honokiol, the level of phosphorylated Smad2/3 was significantly increased following $1 \mathrm{~h}$ of TGF- $\beta 1$ stimulation. However, honokiol treatment markedly decreased the level of phosphorylated Smad2/3 in a dose-dependent manner (Fig. 4A-C). Similar results were also observed by immunofluorescence staining, which revealed the TGF- $\beta 1$-induced nuclear translocation of Smad3 (Fig. 4D and E). These results demonstrated that honokiol suppressed TGF- $\beta 1$ signalling by inhibiting the sustained phosphorylation and nuclear translocation of Smad2/3.

Honokiol suppresses TGF- $\beta 1$-induced MAPK pathway activation. Based on previous studies, TGF- $\beta 1$ activates MAPK signalling in a Smad2/3-independent manner $(24,41)$. Therefore, the present study further examined the effects of honokiol on the levels of phosphorylated ERK, JNK and p38 by western blot analysis. Compared with the control treatment, TGF- $\beta 1$ notably increased the levels of phosphorylated ERK, p38 and JNK, while honokiol treatment resulted in significantly lower levels of p-p38 and p-JNK, but not p-ERK, in a dose-dependent manner (Fig. 5). These findings provide evidence that the protective effects of honokiol are involved in the inhibition of the phosphorylation of p38 and JNK MAPKs and the inhibition of the Smad2/3 pathway.

Honokiol attenuates EF in rats post-laminectomy in vivo. To ensure the safety of the dose of honokiol (10 and $20 \mathrm{mg} / \mathrm{kg}$ ) used in the present study, a toxicological anlasis was performed. No hepatotoxicity or death were observed until the rats were sacrificed (Table SI and Fig. S1). To determine the therapeutic effects of honokiol on EF in vivo, a rat model of laminectomy was established. The grade scores of epidural scar adhesion were obtained to assess the adhesion of the EF specimens according to a previous study (36). Macroscopically, the epidural scar adhesions in the control group were severe and dense around the laminectomy sites, and these epidural scar adhesions were clearly ameliorated by honokiol treatment (Table II). Of note, in the sham group, no scar tissue formation adjacent to the dura mater was observed due to the intact lamina. Therefore, the samples in the sham 

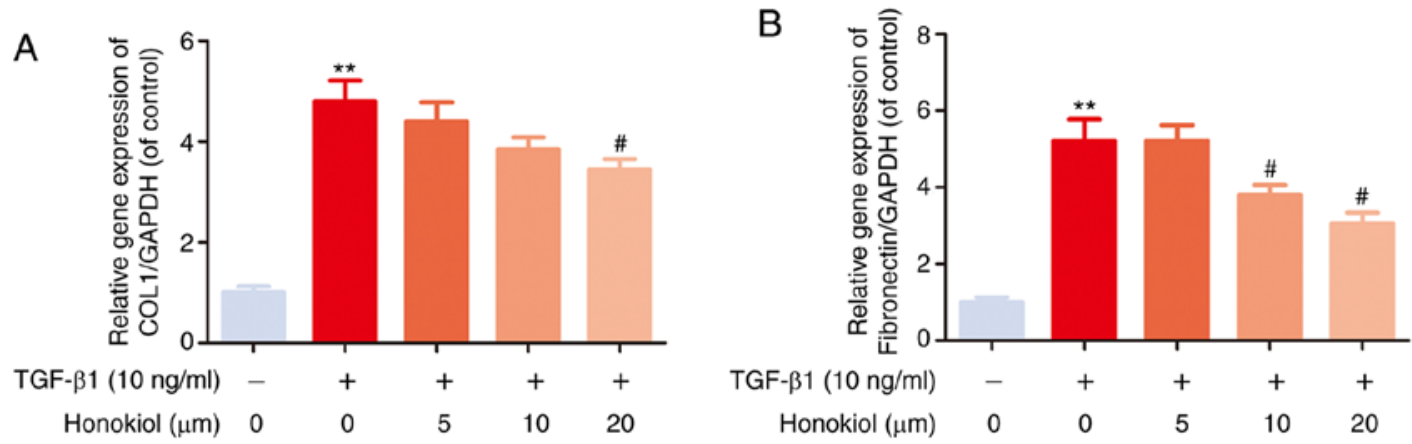

C

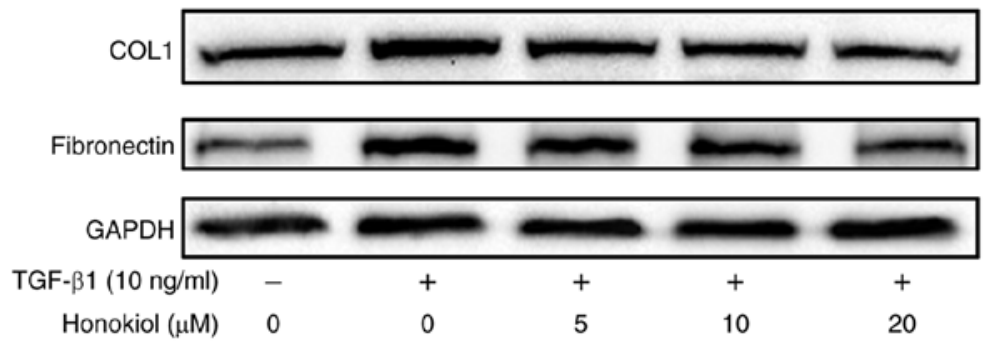

D

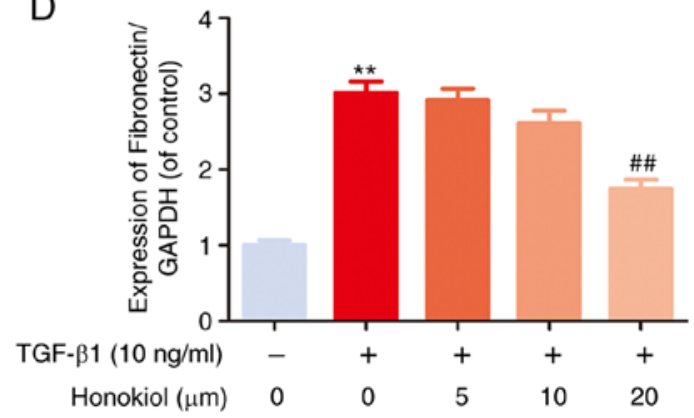

$\mathrm{E}$

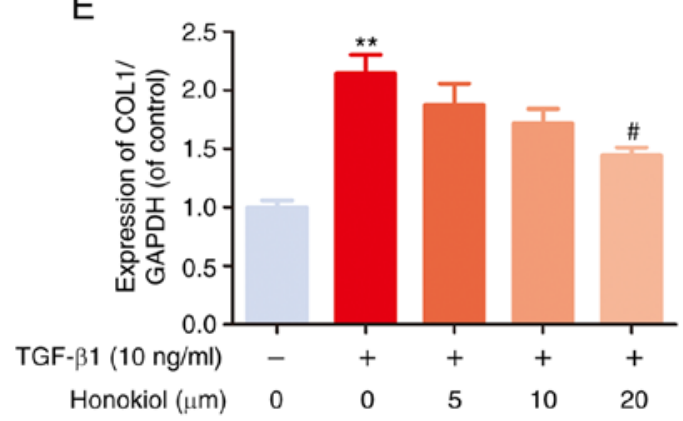

Figure 2. Effect of honokiol on TGF- $\beta 1$-induced ECM production by fibroblasts. (A and B) The cellular levels expression of type I collagen and fibronectin were measured by real-time PCR. The expression levels of these genes were normalized to the expression of GAPDH. (C) Fibroblasts treated with TGF- $\beta 1$, alone or with the indicated concentrations of honokiol, then, harvested for the measurement of type I collagen and fibronectin by western blot. (D and E) Bar diagram of type I collagen and fibronectin expression. Data are presented as the means $\pm \mathrm{SEM},{ }^{* * *} \mathrm{P}<0.01$, vs. the control group. ${ }^{*} \mathrm{P}<0.05,{ }^{\# /} \mathrm{P}<0.01$ compared with the TGF- $\beta 1$-stimulated group; $\mathrm{n}=3$.

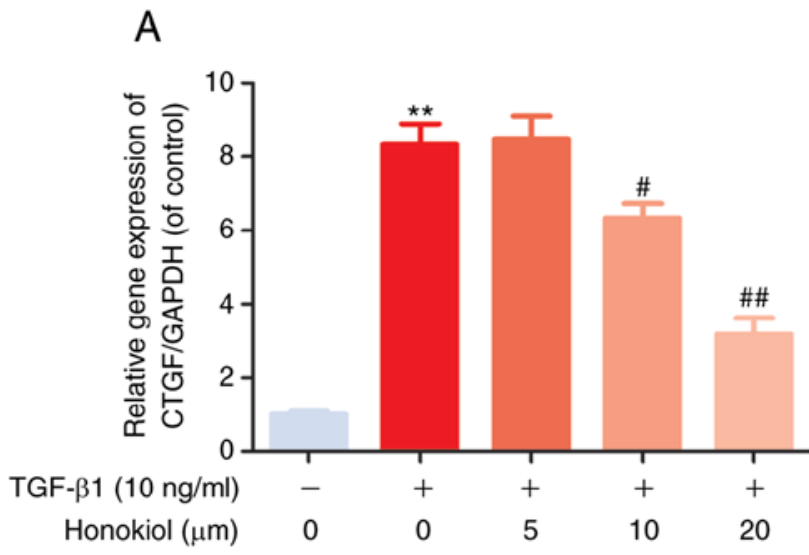

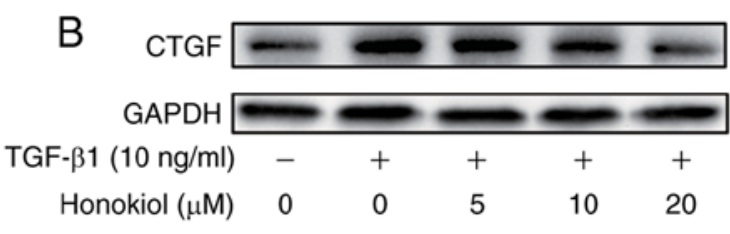

C

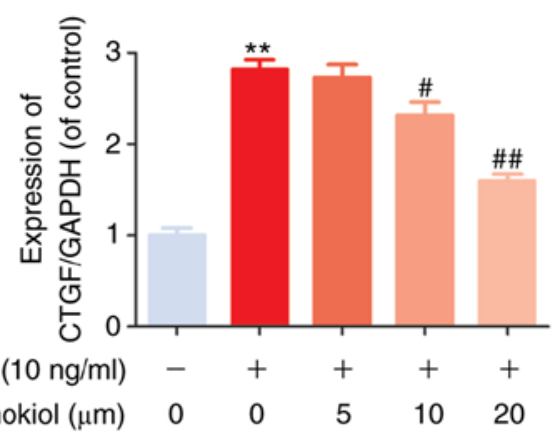

Figure 3. Effect of honokiol on CTGF in TGF- $\beta 1$-stimulated fibroblasts. (A) The cellular levels expression of CTGF was measured by RT-qPCR. The expression level of this gene was normalized to the expression of GAPDH. (B) Fibroblasts treated with TGF- $\beta 1$, alone or with the indicated concentrations of honokiol, then, harvested for the measurement of CTGF by western blot analysis. (C) Bar diagram of CTGF expression. Data are presented as the means \pm SEM, ${ }^{* *} \mathrm{P}<0.01$, vs. the control group. ${ }^{\#} \mathrm{P}<0.05,{ }^{\# \#} \mathrm{P}<0.01$ compared with the TGF- $\beta 1$-stimulated group; $\mathrm{n}=3$. 
A

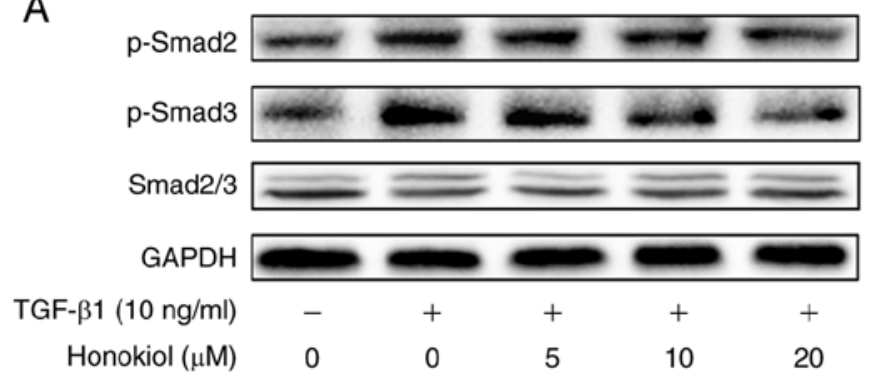

D
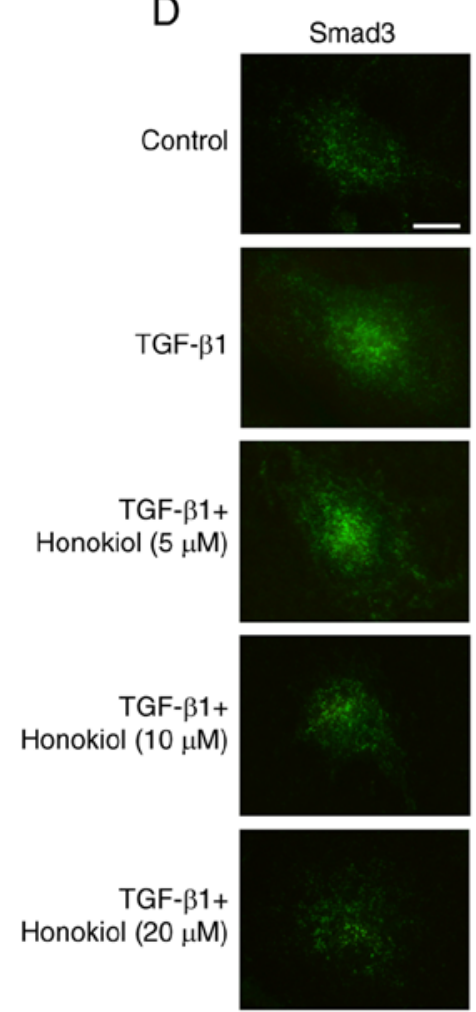
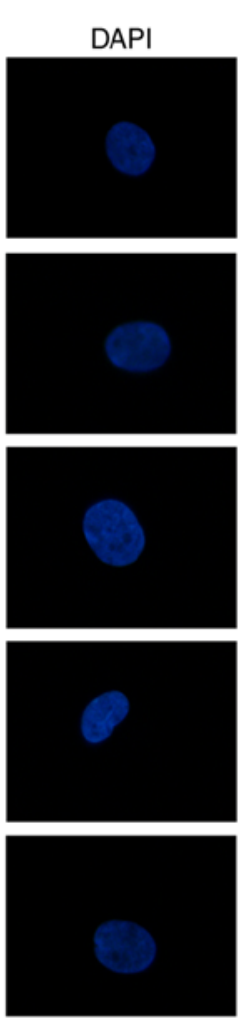
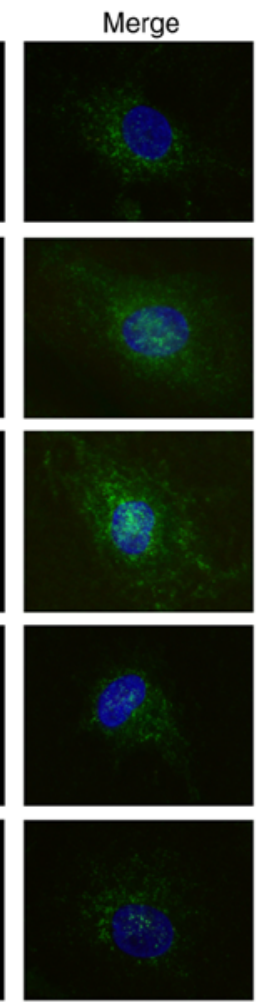

B

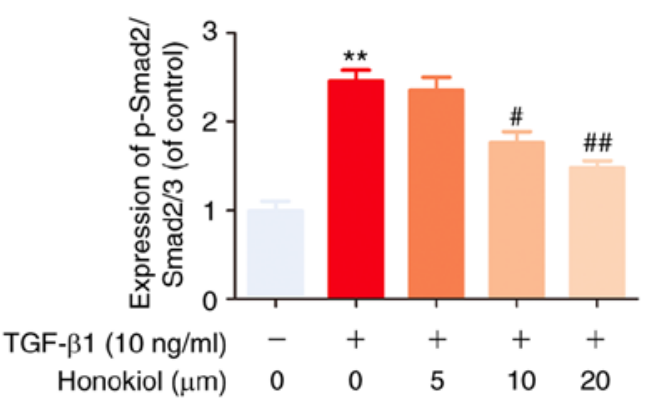

\section{C}

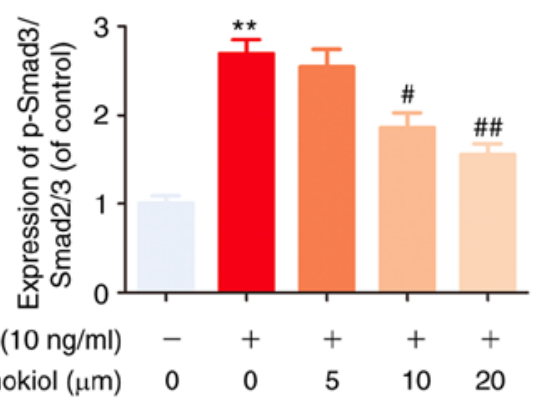

E

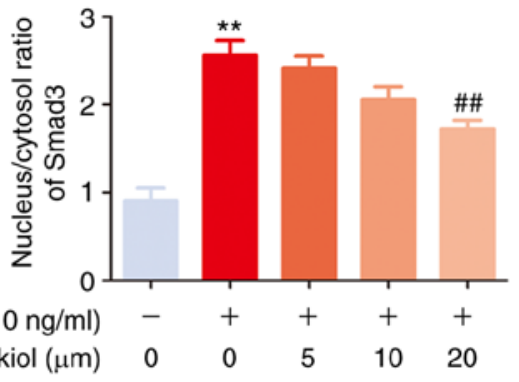

Figure 4. Effect of honokiol on TGF- $\beta 1$-induced Smad2/3 pathway activation. (A) Fibroblasts were pre-treated with honokiol for 2 h, and TGF- $\beta 1$ was added for an additional $1 \mathrm{~h}$. The cell lysates were then examined for the expression of p-Smad2, p-Smad3, and Smad2/3 by western blot analysis. (B and C) The ratios of the intensity of p-Smad 2 and p-Smad3 relative to Smad2/3. (D) Fibroblasts were treated with TGF- $\beta 1$ and/or various concentrations (5, 10 or $20 \mu \mathrm{M})$ of honokiol for $2 \mathrm{~h}$ prior to confocal microscopy (scale bar, $10 \mu \mathrm{m}$ ). (E) The nuclear/cytosolic ratio of Smad 3 staining was measured. Data are presented as the means $\pm \mathrm{SEM},{ }^{* *} \mathrm{P}<0.01$, vs. the control group. ${ }^{\#} \mathrm{P}<0.05,{ }^{\# \#} \mathrm{P}<0.01$ compared with the TGF- $\beta 1$-stimulated group; $\mathrm{n}=3$.

group were only subjected to H\&E staining (data not shown). A corresponding anti-EF effect was also observed in the histological analysis. Compared with that in the control group, the degree of EF adhesion in the honokiol group was moderate, and only loosened or scant scar adhesion was observed in the laminectomy areas (Fig. 6A). Consistent with the histological findings, the fibroblast counts in the H\&E images revealed that the number of fibroblasts was significantly lower in the honokiol groups (Fig. 6B). Similar results were also observed in the collagen tissues by Masson's trichrome staining. The control group exhibited a much higher collagen density in the epidural tissue, while the honokiol group exhibited only scant amounts of collagen tissue (Fig. 7A), which was consistent with the results of the HPC analysis (Fig. 7B). Moreover, the production of fibronectin and type I collagen in the scar tissues was also decreased at the protein level by honokiol treatment (Fig. 7C and D). These therapeutic effects of honokiol on EF occurred in a dose-dependent manner. Taken together, these results indicated that honokiol ameliorated the progression of EF in vivo and may be involved in the inhibition of excessive fibroblast proliferation and ECM overproduction, which is consistent with the in vitro findings.

Potential molecular mechanism involved in honokiol treatment in fibroblasts. Honokiol attenuated TGF- $\beta 1$ induced excessive fibroblast proliferation and the synthesis of ECM components in rats post-laminectomy via suppressing Smad2/3 and MAPK signalling pathways (Fig. 8).

\section{Discussion}

Fibrosis of the local dura mater following laminectomy, which is not uncommon, leads to worse patient outcomes $(42,43)$. The current treatment options, namely, conservative treatment and 
A

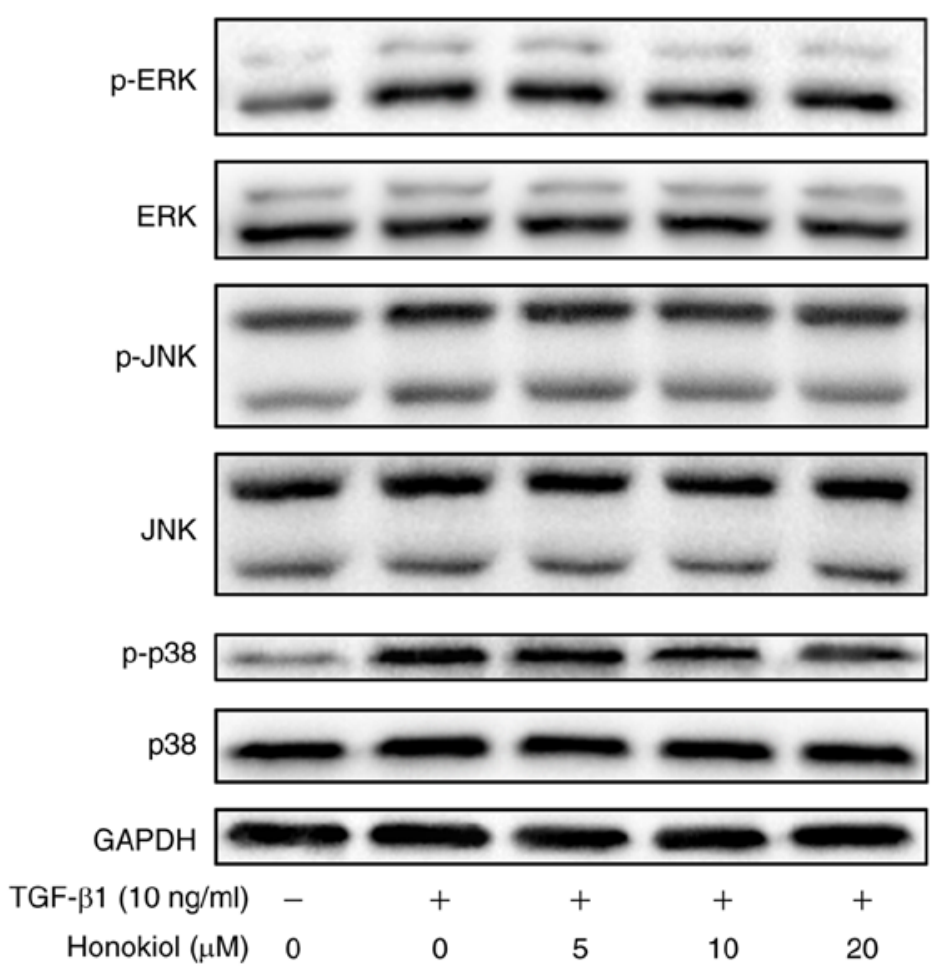

B

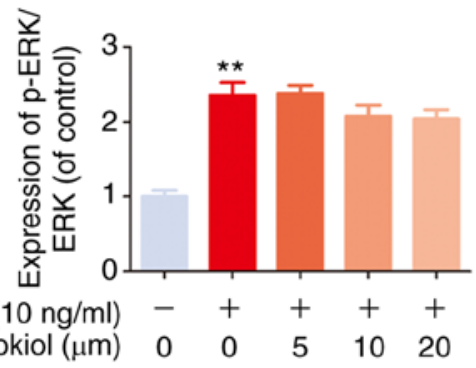

$\mathrm{C}$

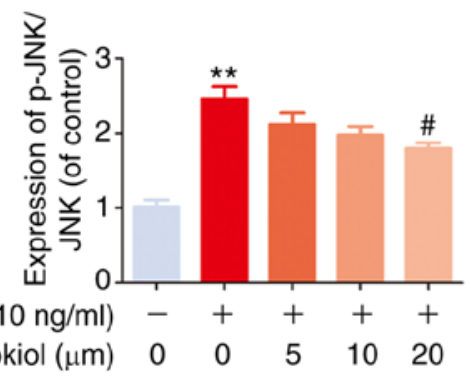

$\mathrm{D}$

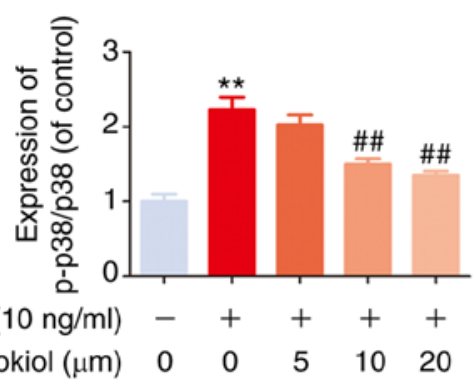

Figure 5. Effects of honokiol on the MAPK pathway in TGF- $\beta 1$-stimulated fibroblasts. (A) The effects of honokiol on the MAPK signalling pathway were assessed by western blot analysis to detect the expression of phosphorylated ERK, JNK and p38. The cell lysates were prepared from fibroblasts pre-treated with honokiol for $2 \mathrm{~h}$ and subsequently induced by TGF- $\beta 1$ for $1 \mathrm{~h}$. (B-D) Bar diagrams of p-ERK, p-JNK andp-p38 relative to total ERK, JNK, and p38, respectively. Data are presented as the means $\pm \mathrm{SEM},{ }^{* *} \mathrm{P}<0.01$, vs. the control group. ${ }^{\#} \mathrm{P}<0.05,{ }^{\# \#} \mathrm{P}<0.01$ compared with the TGF- $\beta 1$-stimulated group; $\mathrm{n}=3$.
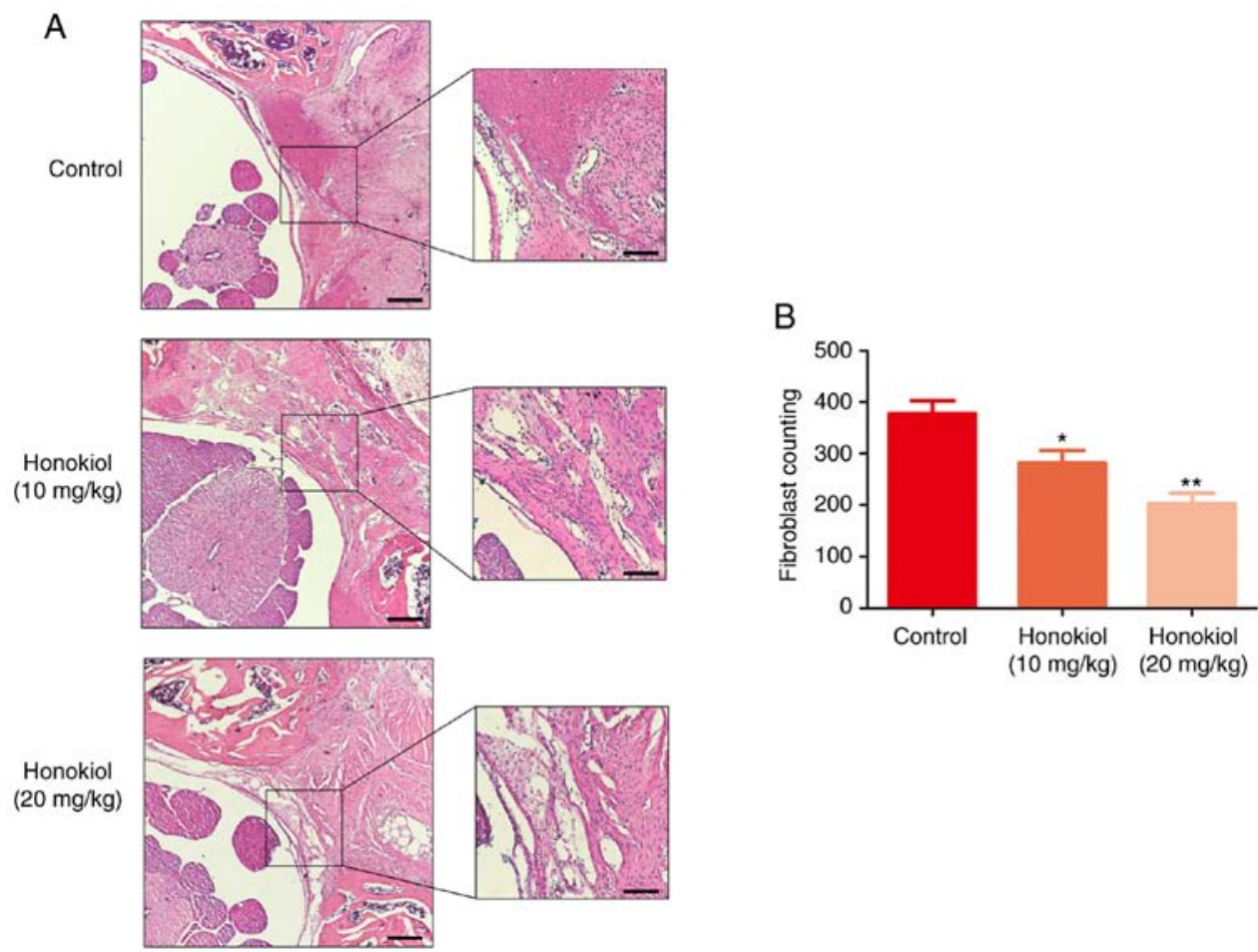

Figure 6. Effect of honokiol on epidural scar tissue in post-laminectomy rats. (A) Representative haematoxylin and eosin staining of samples were from different experimental groups at 4 weeks post-operatively ( $\mathrm{x} 40$ and x100 magnification; scale bars, 250 and $100 \mu \mathrm{m}$, respectively). (B) The number of fibroblasts was counted in selected areas under optical microscopy in each group. Data are presented as the means $\pm \mathrm{SEM},{ }^{*} \mathrm{P}<0.05,{ }^{* *} \mathrm{P}<0.01$, vs. the control group; $\mathrm{n}=6$. 
A

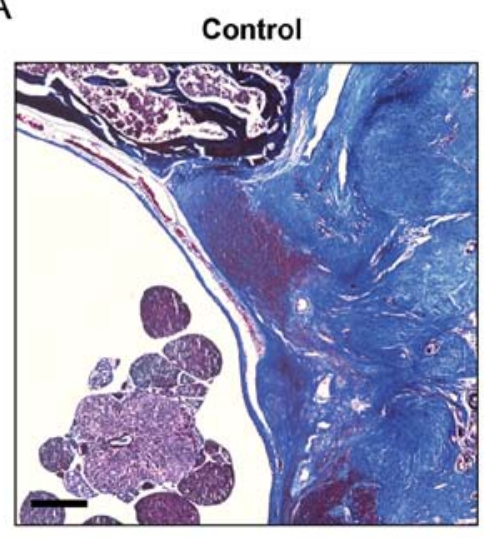

B

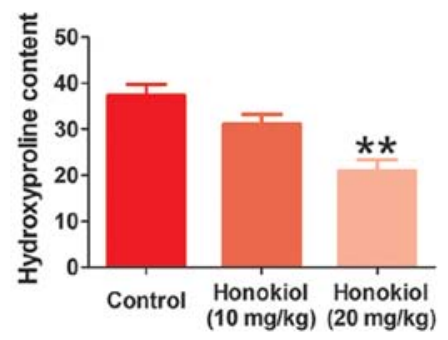

c

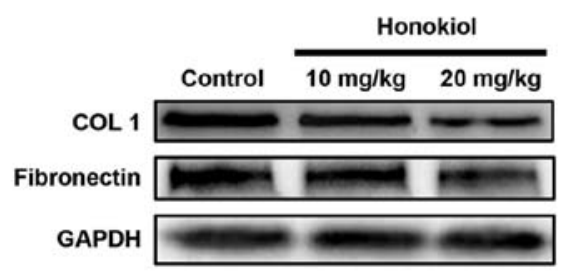

Honokiol $(10 \mathrm{mg} / \mathrm{kg})$
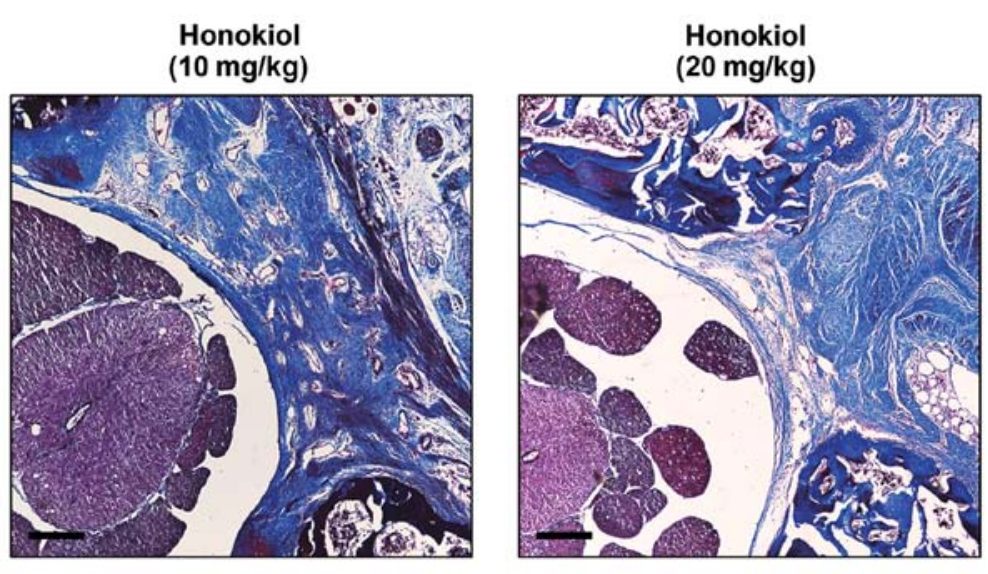

$\mathrm{D}$

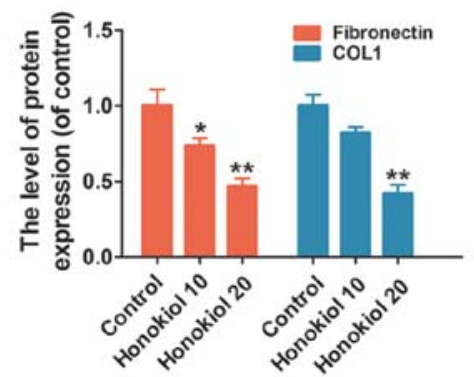

Figure 7. Effect of honokiol on ECM in epidural scar tissue in vivo. (A) Masson's trichrome staining was used to demonstrate the collagen density of epidural adhesion tissues in each group under optical microscopy (x40 magnification; scale bar, $250 \mu \mathrm{m}$ ). (B) The assessment of fibrosis was performed by hydroxyproline content analysis in each group. (C) The protein expression of type I collagen and fibronectin were detected by western blotting in each group. (D) Bar diagram of type I collagen and fibronectin expression in each group. Data are presented as the means $\pm \mathrm{SEM},{ }^{*} \mathrm{P}<0.05,{ }^{* *} \mathrm{P}<0.01$, vs. the control group; $\mathrm{n}=6$.

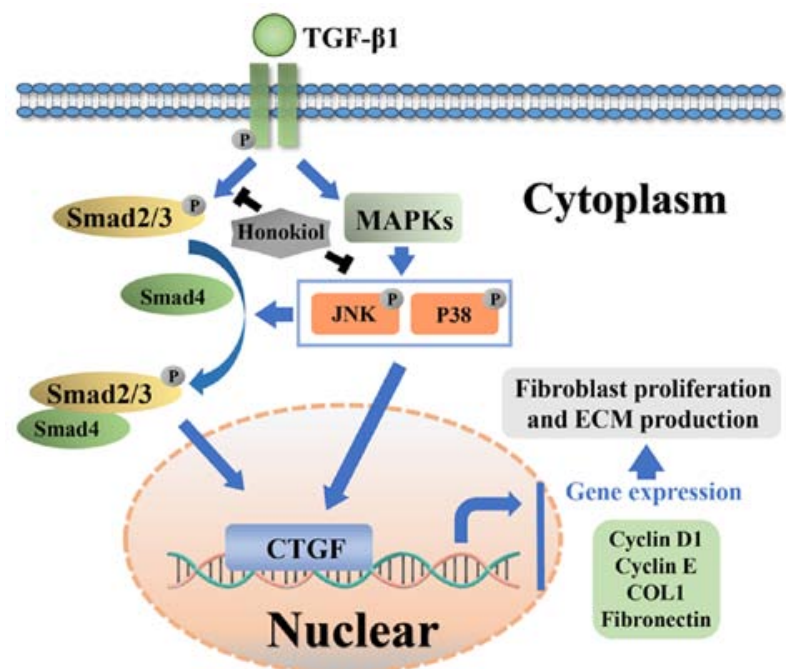

Figure 8. Schematic of the potential protective effects of honokiol in epidural fibrosis development.

scar excision, are unsatisfactory (44). Therefore, biological therapies are increasingly being investigated. Honokiol, an extract of Magnolia officinalis, exhibits potent anti-proliferative and anti-fibrotic effects $(30,31)$. The present study simultaneously used primary fibroblasts and a post-laminectomy rat model to investigate the anti-EF effect of honokiol. Consistent with the biological activities of honokiol described in previous studies $(30,31)$, the present study found that honokiol attenuated EF development by inhibiting excessive fibroblast proliferation and ECM overproduction induced by TGF- $\beta 1$ in primary fibroblasts, and the anti-EF effect was further confirmed in a rat model post-laminectomy.

Fibroblasts are responsible for the majority of scar tissue, and trigger the fibrosis of various tissues and organs. During scar formation, fibroblasts rapidly proliferate and produce large quantities of ECM components, including type collagen I and III and fibronectin $(45,46)$, which is widely considered to be the predominant cause of EF following lumbar laminectomy (15). Therefore, accumulating evidence emphasizes that it is crucial to suppress excessive fibroblast proliferation and ECM production during the tissue remodelling associated with EF (13-15). TGF- $\beta 1$, a cytokine that regulates various cellular functions, is reportedly the key initiating factor of EF. Elevated TGF- $\beta 1$ levels in scar tissue trigger aberrant fibroblast proliferation and ECM overproduction (14,16-18). In the present study, it was found that honokiol exerted a marked anti-proliferative effect on TGF- $\beta 1$-treated fibroblasts, which was confirmed using EdU incorporation assays and western blot analysis of cyclin D1 and cyclin E, major important molecules involved in proliferation. Moreover, TGF- $\beta 1$-induced fibrosis was accompanied by significant increases in the expression levels of type I collagen and fibronectin (at both the gene and protein levels) in primary fibroblasts; these increases were effectively reversed by honokiol in a dose-dependent manner. To further explore the underlying mechanism, the effect of honokiol on CTGF was determined. CTGF, a matricellular protein of the CCN family of ECM-associated proteins that is minimally expressed in normal adult tissue but strongly upregulated in fibrotic tissue (47), has been proven to 
participate in TGF- $\beta 1$-dependent fibrosis by regulating proliferation and ECM production in various cell types (48-50). CTGF has been reported to mediate the TGF- $\beta 1$-induced upregulation of collagen type I in fibroblasts (51). An increased CTGF expression in epidural scar tissue plays a key role in EF development by stimulating TGF- $\beta 1$-induced fibroblast proliferation and ECM production, as well as collagen and fibronectin synthesis (13). As was expected, it was found that TGF- $\beta 1$ treatment significantly stimulated the production of CTGF at both the gene and protein levels, which was reversed by honokiol in a dose-dependent manner. Thus, these results suggested that honokiol may protect against excessive TGF- $\beta 1$-induced fibroblast proliferation and ECM overproduction by inhibiting CTFG during EF. The data of the present study are in agreement with those of previous studies in which honokiol protected against both hypertrophic scarring and renal fibrosis $(30,31)$.

TGF- $\beta 1$ and its downstream signalling cascades play vital roles in initiating the pathological mechanisms underlying EF (51). The incubation of cells with TGF- $\beta$ leads to a long-lasting increase in CTGF (52). Subsequently, CTGF acts as an extracellular adapter protein by binding to a transmembrane receptor serine threonine kinase (TGF- $\beta$ receptor II) through its cysteine-rich domain, and thus helps to induce the phosphorylation of another serine threonine kinase complex (TGF- $\beta$ receptor I/ALK5) (53). In turn, phosphorylated ALK5 induces the phosphorylation of Smad2 and Smad3, which then bind to Smad4 in order to form a heteromeric Smad complex to activate the transcription of target genes, including CTGF, triggering the transcription of genes encoding ECM proteins (47,54-57). Notably, of the Smad transcription factors, only Smad3 seems to be required for the regulation of TGF- $\beta$-mediated CTGF promoter activation in primary osteoblasts (58). Moreover, the TGF- $\beta 1$-induced activation of the Smad2/3 pathway has also been suggested to regulate several important cell functions, including differentiation, proliferation and ECM component synthesis $(23,24)$. However, TGF- $\beta 1$-induced CTGF expression can be blocked via Smad-dependent transcription (59). It has been demonstrated that the inhibition of the Smad2/3 pathway markedly ameliorated keloid expression by inhibiting cell proliferation and ECM synthesis, and keloid scarring is similar to that characterizing EF $(20,60)$. Therefore, the present study explored the molecular mechanisms underlying the anti-fibrotic effects of honokiol by suppressing Smad signalling. As was expected, Smad2 and Smad3 phosphorylation were increased by TGF- $\beta 1$ stimulation; honokiol significantly attenuated this effect in a dose-dependent manner, which was further confirmed by examining the TGF- $\beta 1$-induced nuclear translocation of immunofluorescent Smad3. The present study revealed that honokiol attenuated fibroblast proliferation and ECM production by inhibiting Smad2/3 phosphorylation and nuclear translocation. In addition, TGF- $\beta 1$ also acts via non-canonical pathways in a cell-specific manner. The TGF- $\beta 1$-mediated induction of CTGF is further modulated by MAPK signalling $(61,62)$. It has been suggested that the inhibition of any two MAPKs, namely, ERK, p38, or JNK, completely inhibits the TGF- $\beta 1$-mediated induction of CTGF in lung fibroblasts (47). Moreover, TGF- $\beta 1$-induced MAPK activation has been reported to contribute to the modulation of the TGF- $\beta 1$-induced phosphorylation and the nuclear translocation of Smad2/3 signalling pathway components $(41,63)$. Although the molecular mechanisms of the crosstalk between the MAPK and Smad signalling pathways are not yet fully understood, interest in the important role of the MAPK-Smad crosstalk pathway in fibrosis is growing (23). Furthermore, a recent study demonstrated that MAPK signalling played a critical role in liver injury and hepatic stellate cell proliferation (64). p38 MAPK signalling increases the half-life and stability of type I collagen mRNA (65). Honokiol has also been reported to suppress the activity of the MAPK signalling pathway by inhibiting the phosphorylation of p38 and JNK in human epithelial cells (66). As shown in in the present study, TGF- $\beta 1$ also activated the MAPK signalling pathway. Of note, honokiol preconditioning significantly reduced the TGF- $\beta 1$-induced phosphorylation of p38 and JNK, but not p-ERK, which is consistent with the findings of previous studies $(32,66)$. Taken together, it was surmised that the anti-EF effects of honokiol may be associated with the inhibition of CTGF via the Smad2/3 and MAPK (p38 and JNK) pathways.

The therapeutic effects of honokiol were further assessed in a rat model of EF post-laminectomy. Compared to the honokiol-treated group, the control group exhibited more severe epidural adhesion and higher numbers of fibroblasts. Honokiol significantly reduced collagen density, hydroxypropyl cellulose, and fibronectin and type I collagen production by epidural scar tissue, indicating that honokiol could ameliorate $\mathrm{EF}$ in vivo. These results and those of the in vitro experiments further demonstrated that honokiol has potential value in preventing epidural scar adhesion.

However, the present study still has some limitations. First, the present study did not assess the effects of a MAPK pathway inhibitor, such as the p38 kinase inhibitor SB203580 or the JNK inhibitor SP600125. Second, in addition to fibroblast proliferation and ECM deposition, the lack of further mechanistic analysis to determine the involvement of fibroblast activation, migration and differentiation is another limitation of the present study that will be investigated in future studies. Third, it would be better to further confirm whether honokiol arrests cell growth by other assays, such as flow cytometry.

In conclusion, the present study demonstrates that honokiol may serve as a promising and effective therapeutic agent for the treatment of EF in the future. The potential mechanisms involved in its protective effects are the reversal of aberrant fibroblast proliferation and ECM production by inhibiting the Smad2/3 and MAPK pathways.

\section{Acknowledgements}

Not applicable.

\section{Funding}

The present study was supported by the National Natural Science Foundation of China (grant no. 81371988), the Zhejiang Public service technology research program/social development (grant no. LGF18H060008), the Science and Technology Innovation Activity Plan for University Students in Zhejiang Province (grant no. 2019R413007), and the Zhejiang Provincial Public Welfare Science and Technology Project (grant no. 2017C33100). 


\section{Availability of data and materials}

The datasets used and/or analysed during the current study are available from the corresponding author on reasonable request.

\section{Authors' contributions}

DX, QW and HJ conceived and designed the experiments. DX, WZ and XH performed the experiments. TQ, JS, FQ, CL and QW analysed the data. DX, QW and HJ were involved in the drafting of the manuscript or critically revising it for important intellectual content. All authors read and approved the final version of the manuscript.

\section{Ethics approval and consent to participate}

All experimental procedures for animal studies were carried out in compliance with the principles of International Laboratory Animal Care and the experimental protocol was approval by the Animal Care and Use Committee at the Wenzhou Medical College (approval no. wydw2017-0007).

\section{Patient consent for publication}

Not applicable.

\section{Competing interests}

The authors declare that they have no competing interests.

\section{References}

1. Liu P, Chen H, Yan L and Sun Y: Laminin alpha5 modulates fibroblast proliferation in epidural fibrosis through the PI3K/AKT/mTOR signaling pathway. Mol Med Rep 21: 1491-1500, 2020.

2. Burton CV: Causes of failure of surgery on the lumbar spine: Ten-Year follow-up. Mt Sinai J Med 58: 183-187, 1991.

3. Burton CV, Kirkaldy-Willis WH, Yong-Hing K and Heithoff KB: Causes of failure of surgery on the lumbar spine. Clin Orthop Relat Res 157: 191-199, 1981.

4. Chen F, Zuo Z, Wang K, Zhang C, Gong H, Ye F, Ji A and Tao H: Study on salvianolic acid $\mathrm{B}$ in the reduction of epidural fibrosis in laminectomy rats. BMC Musculoskelet Disord 15: 337, 2014.

5. Zhang K, Zhao J, Su W, Lu R and Lv P: Immunomodulatory effectiveness of licofelone in preventing epidural fibrosis in post-laminectomy rat. Eur J Orthop Surg Traumatol 25: S63-S68, 2015 .

6. Kasimcan MO, Bakar B, Aktaş S, Alhan A and Yilmaz M: Effectiveness of the biophysical barriers on the peridural fibrosis of a postlaminectomy rat model: An experimental research. Injury 42: 778-781, 2011.

7. Wu CY, Huang YH, Lee JS, Tai TW, Wu PT and Jou IM: Efficacy of topical cross-linked hyaluronic acid hydrogel in preventing post laminectomy/laminotomy fibrosis in a rat model. J Orthop Res 34: 299-306, 2016.

8. Lubina ZI, Baranovic S, Karlak I, Novacic K, Potocki-Karacic T and Lovrić D: The grading model for the assessment of the total amount of epidural fibrosis in postoperative lumbar spine. Eur Spine J 22: 892-897, 2013.

9. Ross JS, Robertson JT, Frederickson RC, Petrie JL, Obuchowski N, Modic MT and deTribolet N: Association between peridural scar and recurrent radicular pain after lumbar discectomy: Magnetic resonance evaluation. ADCON-L european study group. Neurosurgery 38: 855-861, 1996.

10. Wang H, Sun W, Fu D, Shen Y, Chen YY and Wang LL: Update on biomaterials for prevention of epidural adhesion after lumbar laminectomy. J Orthop Translat 13: 41-49, 2018.
11. Brzezicki G,Jankowski R, Blok T, Klimczak A, Szymas J, Huber J, Szukala A, Siemionow M and Nowak S: Postlaminectomy osteopontin expression and associated neurophysiological findings in rat peridural scar model. Spine (Phila Pa 1976) 36: 378-385, 2011.

12. Yakovlev AE, Timchenko AA and Parmentier AM: Spinal cord stimulation and sacral nerve stimulation for postlaminectomy syndrome with significant low back pain. Neuromodulation 17: 763-765, 2014.

13. Xu H, Liu C, Sun Z, Guo X, Zhang Y, Liu M and Li P: CCN5 attenuates profibrotic phenotypes of fibroblasts through the smad6-CCN2 pathway: Potential role in epidural fi brosis. Int J Mol Med 36: 123-129, 2015.

14. Yan L, Li X, Wang J, Sun Y, Wang D, Gu J, He J, Hu H, Chen G, Wang $Q$ and Feng X: Immunomodulatory effectiveness of tacrolimus in preventing epidural scar adhesion after laminectomy in rat model. Eur J Pharmacol 699: 194-199, 2013.

15. Zhang C, Kong X, Liu C, Liang Z, Zhao H, Tong W, Ning G, Shen W, Yao L and Feng S: ERK2 small interfering RNAs prevent epidural fibrosis via the efficient inhibition of collagen expression and inflammation in laminectomy rats. Biochem Biophys Res Commun 444: 395-400, 2014.

16. Sun HH, Wang JC, Feng XM, Zhu SL and Cai J: Allicin inhibits proliferation and promotes apoptosis of human epidural scar fibroblasts. World Neurosurg 136: e460-e468, 2020.

17. Penn JW, Grobbelaar AO and Rolfe KJ: The role of the TGF- $\beta$ family in wound healing, burns and scarring: A review. Int J Burns Trauma 2: 18-28, 2012.

18. Zhang C, Kong X, Zhou H, Liu C, Zhao X, Zhou X, Su Y, Sharma HS and Feng S: An experimental novel study: Angelica sinensis prevents epidural fibrosis in laminectomy rats via downregulation of hydroxyproline, IL- 6 , and TGF- $\beta 1$. Evid Based Complement Alternat Med 2013: 291814, 2013.

19. Lakos G, Takagawa S, Chen SJ, Ferreira AM, Han G, Masuda K, Wang XJ, DiPietro LA and Varga J: Targeted disruption of TGF-beta/Smad3 signaling modulates skin fibrosis in a mouse model of scleroderma. Am J Pathol 165: 203-217, 2004.

20. Wu CS, Wu PH, Fang AH and Lan CC: FK506 inhibits the enhancing effects of transforming growth factor (TGF)- $\beta 1$ on collagen expression and TGF- $\beta /$ Smad signalling in keloid fibroblasts: Implication for new therapeutic approach. $\mathrm{Br}$ J Dermatol 167: 532-541, 2012.

21. Massagué J and Wotton D: Transcriptional control by the TGF-beta/smad signaling system. EMBO J 19: 1745-1754, 2000.

22. Nakao A, Imamura T, Souchelnytskyi S, Kawabata M, Ishisaki A, Oeda E, Tamaki K, Hanai J, Heldin CH, Miyazono K and Dijke Pt: TGF-beta receptor-mediated signalling through smad2, smad3 and smad4. EMBO J 16: 5353-5362, 1997.

23. Javelaud D and Mauviel A: Mammalian transforming growth factor-betas: Smad signaling and physio-pathological roles. Int J Biochem Cell Biol 36: 1161-1165, 2004.

24. Derynck R and Zhang YE: Smad-Dependent and smad-independent pathways in TGF-beta family signalling. Nature 425 : 577-584, 2003.

25. Fried LE and Arbiser JL: Honokiol, a multifunctional antiangiogenic and antitumor agent. Antioxid Redox Signal 11: 1139-1148, 2009.

26. Lee YJ, Lee YM, Lee CK, Jung JK, Han SB and Hong JT: Therapeutic applications of compounds in the magnolia family. Pharmacol Ther 130: 157-176, 2011.

27. Woodbury A, Yu SP, Wei L and García P: Neuro-Modulating effects of honokiol: A review. Front Neurol 4: 130, 2013.

28. Pan J, Lee Y, Wang Y and You M: Honokiol targets mitochondria to halt cancer progression and metastasis. Mol Nutr Food Res 60: 1383-1395, 2016.

29. Shen JL, Man KM, Huang PH, Chen WC, Chen DC, Cheng YW, Liu PL, Chou MC and Chen YH: Honokiol and magnolol as multifunctional antioxidative molecules for dermatologic disorders. Molecules 15: 6452-6465, 2010.

30. Zhao D, Wang Y, Du C, Shan S, Zhang Y, Du Z and Han D: Honokiol alleviates hypertrophic scar by targeting transforming growth factor- $\beta / \operatorname{smad} 2 / 3$ signaling pathway. Front Pharmacol 8 : 206, 2017.

31. Chiang CK, Sheu ML, Lin YW, Wu CT, Yang CC, Chen MW, Hung KY, Wu KD and Liu SH: Honokiol ameliorates renal fibrosis by inhibiting extracellular matrix and pro-inflammatory factors in vivo and in vitro. Br J Pharmacol 163: 586-597, 2011.

32. Elfeky MG, Mantawy EM, Gad AM, Fawzy HM and El-Demerdash E: Mechanistic aspects of antifibrotic effects of honokiol in con A-induced liver fibrosis in rats: Emphasis on TGF- $3 /$ SMAD/MAPK signaling pathways. Life Sci 240: 117096 , 2020. 
33. Sun Y, Wang LX, Wang L, Sun SX, Cao XJ, Wang P and Feng L: A comparison of the effectiveness of mitomycin $\mathrm{C}$ and 5-fluorouracil in the prevention of peridural adhesion after laminectomy. J Neurosurg Spine 7: 423-428, 2007.

34. Livak KJ and Schmittgen TD: Analysis of relative gene expression data using real-time quantitative PCR and the 2(-Delta Delta $\mathrm{C}(\mathrm{T})$ ) method. Methods 25: 402-408, 2001.

35. American Veterinary Medical Association (AVMA): AVMA Guidelines for the Euthanasia of Animals: 2020 Edition. AVMA Schaumburg, IL, 2020. https://www.avma.org/sites/default/ files/2020-01/2020-Euthanasia-Final-1-17-20.pdf.

36. Rydell N: Decreased granulation tissue reaction after installment of hyaluronic acid. Acta Orthop Scand 41: 307-311, 1970

37. Fukui $\mathrm{N}$, Tashiro T, Hiraoka $\mathrm{H}$, Oda $\mathrm{H}$ and Nakamura $\mathrm{K}$ : Adhesion formation can be reduced by the suppression of transforming growth factor-beta1 activity. J Orth Res 18: 212-219, 2000.

38. Möröy T and Geisen C: Cyclin E. Int J Biochem Cell Biol 36: 1424-1439, 2004.

39. Maggioni D, Nicolini G, Rigolio R, Biffi L, Pignataro L, Gaini R and Garavello W: Myricetin and naringenin inhibit human squamous cell carcinoma proliferation and migration in vitro. Nutr Cancer 66: 1257-1267, 2014.

40. Schnittger A and De Veylder L: The dual face of cyclin B1. Trends Plant Sci 23: 475-478, 2018.

41. Engel ME, McDonnell MA, Law BK and Moses HL: Interdependent SMAD and JNK signaling in transforming growth factor-beta-mediated transcription. J Biol Chem 274 37413-37420, 1999.

42. Dai J, Li X, Yan L, Chen H, He J, Wang S, Wang J and Sun Y: The effect of suramin on inhibiting fibroblast proliferation and preventing epidural fibrosis after laminectomy in rats. J Orthop Surg Res 11: 108, 2016.

43. Jiao R, Chen H, Wan Q, Zhang X, Dai J, Li X, Yan L and Sun Y: Apigenin inhibits fibroblast proliferation and reduces epidural fibrosis by regulating wnt $3 \mathrm{a} / \beta$-catenin signaling pathway. J Orthop Surg Res 14: 258, 2019.

44. Cruccu G, Aziz TZ, Garcia-Larrea L, Hansson P, Jensen TS, Lefaucheur JP, Simpson BA and Taylor RS: EFNS guidelines on neurostimulation therapy for neuropathic pain. Eur J Neurol 14: 952-970, 2007.

45. Armour A, Scott PG and Tredget EE: Cellular and molecular pathology of HTS: Basis for treatment. Wound Repair Regen 15: S6-S17, 2007.

46. Chrysanthopoulou A, Mitroulis I, Apostolidou E, Arelaki S, Mikroulis D, Konstantinidis T, Sivridis E, Koffa M, Giatromanolaki A, Boumpas DT, et al: Neutrophil extracellular traps promote differentiation and function of fibroblasts. J Pathol 233: 294-307, 2014.

47. Cicha I and Goppelt-Struebe M: Connective tissue growth factor: Context-Dependent functions and mechanisms of regulation. Biofactors 35: 200-208, 2009.

48. Fan WH, Pech M and Karnovsky MJ: Connective tissue growth factor (CTGF) stimulates vascular smooth muscle cell growth and migration in vitro. Eur J Cell Biol 79: 915-923, 2000.

49. Yamanaka O, Saika S, Ikeda K, Miyazaki KI, Kitano A and Ohnishi Y: Connective tissue growth factor modulates extracellular matrix production in human subconjunctival fibroblasts and their proliferation and migration in vitro. Jpn J Ophthalmol 52: $8-15,2008$.

50. Burns WC, Twigg SM, Forbes JM, Pete J, Tikellis C, Thallas-Bonke V, Thomas MC, Cooper ME and Kantharidis P: Connective tissue growth factor plays an important role in advanced glycation end product-induced tubular epithelial-to-mesenchymal transition: Implications for diabetic renal disease. J Am Soc Nephrol 17: 2484-2494, 2006.

51. Jin H, Wang Z, Gu Z, Wu J, Bai X, Shao Z, Miao J, Wang Q, Wang Q and Wang X: Schisandrin B attenuates epidural fibrosis in postlaminectomy rats by inhibiting proliferation and extracellular matrix production of fibroblasts. Phytother Res 33: 107-116, 2019.
52. Kroening S, Solomovitch S, Sachs M, Wullich B and Goppelt-Struebe M: Regulation of connective tissue growth factor (CTGF) by hepatocyte growth factor in human tubular epithelial cells. Nephrol Dial Transplant 24: 755-762, 2009.

53. Ruiz-Ortega M, Rodríguez-Vita J, Sanchez-Lopez E, Carvajal G and Egido J: TGF-Beta signaling in vascular fibrosis. Cardiovasc Res 74: 196-206, 2007.

54. Heldin $\mathrm{CH}$, Miyazono $\mathrm{K}$ and ten Dijke P: TGF-Beta signalling from cell membrane to nucleus through SMAD proteins. Nature 390: 465-471, 1997.

55. Shi Y and Massagué J: Mechanisms of TGF-beta signaling from cell membrane to the nucleus. Cell 113: 685-700, 2003.

56. Schiller M, Javelaud D and Mauviel A: TGF-Beta-induced SMAD signaling and gene regulation: Consequences for extracellular matrix remodeling and wound healing. J Dermatol Sci 35: 83-92, 2004.

57. Ryer EJ, Hom RP, Sakakibara K, Nakayama KI, Nakayama K, Faries PL, Liu B and Kent KC: PKCdelta is necessary for smad3 expression and transforming growth factor beta-induced fibronectin synthesis in vascular smooth muscle cells. Arterioscler Thromb Vasc Biol 26: 780-786, 2006.

58. Arnott JA, Zhang X, Sanjay A, Owen TA, Smock SL, Rehman S, DeLong WG, Safadi FF and Popoff SN: Molecular requirements for induction of CTGF expression by TGF-beta1 in primary osteoblasts. Bone 42: 871-885, 2008.

59. Lin SL, Chen RH, Chen YM, Chiang WC, Lai CF, Wu KD and Tsai TJ: Pentoxifylline attenuates tubulointerstitial fibrosis by blocking smad3/4-activated transcription and profibrogenic effects of connective tissue growth factor. J Am Soc Nephrol 16: 2702-2713, 2005.

60. Phan TT, Lim IJ, Chan SY, Tan EK, Lee ST and Longaker MT: Suppression of transforming growth factor beta/smad signaling in keloid-derived fibroblasts by quercetin: Implications for the treatment of excessive scars. J Trauma 57: 1032-1037, 2004.

61. Fu M, Zhang J, Zhu X, Myles DE, Willson TM, Liu X and Chen YE: Peroxisome proliferator-activated receptor gamma inhibits transforming growth factor beta-induced connective tissue growth factor expression in human aortic smooth muscle cells by interfering with smad3. J Biol Chem 276: 45888-45894, 2001.

62. Kwon S, Munroe X, Crawley SC, Lee HY, Spong S, Bradham D, Gum JR Jr, Sleisenger MH and Kim YS: Expression of connective tissue growth factor in pancreatic cancer cell lines. Int J Oncol 31: 693-703, 2007.

63. Park JH, Yoon J, Lee KY and Park B: Effects of geniposide on hepatocytes undergoing epithelial-mesenchymal transition in hepatic fibrosis by targeting TGF $\beta /$ smad and ERK-MAPK signaling pathways. Biochimie 113: 26-34, 2015

64. Tang N, Zhang YP, Ying W and Yao XX: Interleukin-1 $\beta$ upregulates matrix metalloproteinase-13 gene expression via c-jun $\mathrm{N}$-terminal kinase and p38 MAPK pathways in rat hepatic stellate cells. Mol Med Rep 8: 1861-1865, 2013.

65. Tsukada S, Westwick JK, Ikejima K, Sato N and Rippe RA: SMAD and p38 MAPK signaling pathways independently regulate alpha1(I) collagen gene expression in unstimulated and transforming growth factor-beta-stimulated hepatic stellate cells. J Biol Chem 280: 10055-10064, 2005.

66. Tang X, Yao K, Zhang L, Yang Y and Yao H: Honokiol inhibits $\mathrm{H}(2) \mathrm{O}(2)$-induced apoptosis in human lens epithelial cells via inhibition of the mitogen-activated protein kinase and akt pathways. Eur J Pharmacol 650: 72-78, 2011.

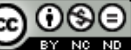

This work is licensed under a Creative Commons Attribution-NonCommercial-NoDerivatives 4.0 International (CC BY-NC-ND 4.0) License. 